\title{
Synergistic Effects of Fumonisins B1 and B2 in Pigs: A
} Review

\author{
Anilce de Araújo Brêtas ${ }^{1}$ and Patrícia Castelo Branco do Vale ${ }^{2}$ \\ 1. The Department of Zootechny, University Federal of Rio Grande do Sul, Agronomia 1486, Porto Alegre, Brazil \\ 2. The Department of Nutrition and Zootechny, University Federal of Sergipe, São Cristóvão 4100, Sergipe, Brazil
}

\begin{abstract}
The productivity of swine farming depends on the large amount of nutrients that may contain mycotoxins. This review addresses the main smoke functions in food, its physical-chemical characteristics, metabolization, immunological factors and preventive measures. Fungal contamination can occur during virtually all stages of the development of the plant organism. The clinical results in animals are dependent on the amount of mycotoxins in their organism associated with the mycotoxin type, leading to pulmonary edema, decreased food intake and weight gain, and reduced ability to move. Pulmonary edema caused by fumonisin (FUMO) is the cause of the disease, but the definitive diagnosis is based on the observation of the lesions and the presence of FUMO in the raw materials of the diet. Prevention can be by use of additives as an adsorbent that can decrease or control existing toxins in the identified diet. It is necessary to have a careful assessment of the benefits of the more stringent prevention standards on the contamination of fumes, as well as their economic losses in the food chain.
\end{abstract}

Key words: Mycotoxins, intoxication, immunosuppressant, swine breeding.

\section{Introduction}

The presence of mycotoxins in food is described as secondary metabolites produced by fungi during the production process and storage of grains, with the possibility of being toxic to humans, animals and plants [1]. Several species of fungi such as Aspergillus, Fusarium, Penicillium, Streptomyces can be found in grains and forage used in food [2].

Several species of fungi may produce the same type of mycotoxin, but a single species of fungus can produce more than one type of toxin [3]. However, the Fusarium species are able to synthesize several mycotoxins [4], and to the trichothecene class, zearalenone (ZON) and fumonisins (FUMO) are the ones that most affect health and productivity in animal husbandry. This genus of pathogenic fungi is economically important, causing damage to maize and sorghum crops every year [5].

More than 500 different mycotoxins are known to

Corresponding author: Anilce de Araújo Brêtas, Ph.D., research field: animal production. exhibit large structural differences with different chemical and physico-chemical properties [6]. Among the toxins considered to be at greatest risk to human and animal health are aflatoxins (AFLA), ochratoxin (OTA), ZON, deoxynivalenol (DON) and FUMO according to Iamanaka et al. [7].

The literature cites that mycotoxins can not be classified only by their mechanism of action given their diversity of chemical structures [8]. The in vitro study may provide the basis for predicting interactions between mycotoxins [9]. Initially, Kubena et al. [10] demonstrated in vivo the additive effects between FUMO B1 and OTA by studies in young turkeys, but it is emphasized that the synergistic interactions between FUMO B1 and OTA depend on the doses used [11].

\section{Metabolic Fungi and Their Characteristics}

FUMO are mycotoxins, secondary metabolites of fungi, especially of the genus Fusarium, being structurally related with: A (A1-A4), B (B1-B4), C 
(C1-C4) and P [12]. However, in greater abundance is FUMO B1 followed by FUMO B2 and in the sequence to FUMO B3 [13] which is considered to be the most toxic.

There are several kinds of FUMOB identified, however the FUMO B1 and FUMO B2 constitute up to $70 \%$ of the FUMOB found in naturally contaminated foods [14]. Fungal species of the genus Fusarium, especially by Fusarium verticillioides is the main producers of these toxins [15].

The fungal growth is sensitive to the minimum temperature for the growth of this, so not necessarily in the minimum and maximum temperature there will be toxin production. The ideal temperature for FUMO production was calculated by means of regression analysis, being $24.5{ }^{\circ} \mathrm{C}$ and $24.3{ }^{\circ} \mathrm{C}\left( \pm 2{ }^{\circ} \mathrm{C}\right)$ for FUMO B1 and FUMO B2, respectively [16].

Mycotoxins are known to maintain toxicity after exposure to elevated processing temperatures. FUMO are thermally stable at temperatures above $150{ }^{\circ} \mathrm{C}$, but can be effectively removed in food samples [17]. However, these thermal processes result in the conversion of intact FUMO into hydrolyzed FUMO which are more cytotoxic than FUMO B1 [18].

The temperature and humidity conditions during the plant development period as well as during the storage period are often the causes of pathogen infection and mycotoxin production [19]. The optimal temperature range for the growth of $F$. verticillioides is between $22.5{ }^{\circ} \mathrm{C}$ and $27.5{ }^{\circ} \mathrm{C}$ and minimum water activity of 0.98 [20].

Contamination with mycotoxins is also affected by climatic factors such as temperature and relative humidity available in pre- and post-harvest [21]. In a study conducted in the state of Paraná, ONO et al. [22] found that the combination of high relative humidity and temperature are key to fungus growth and subsequent contamination with mycotoxins.

As a consequence of the continental dimensions of the country, there is a possibility that the presence and content of mycotoxins in foods produced and consumed are unequal among the different regions [23].

In Brazil, the highest incidence of FUMO contamination occurs in cereals, mainly in the south of the country [24]. FUMO are found mainly in corn and corn products [25].

\section{FUMO in Animal Diet}

Corn meal, an ingredient of high concentration in feed, is generally more attacked by FUMO in many countries, with concentrations of $330 \mu \mathrm{g} / \mathrm{g}$ FUMO B1 already present in pork diets [26]. The species $F$. verticilioides is responsible for the root rot, stem and deterioration of stored maize grains, that is, causing disease in all stages of maize development, whose predominance is asymptomatic plant infection [27].

Animals like humans are exposed to mycotoxins through food. As contamination of food by mycotoxins is difficult to avoid, prevention should occur through strict monitoring of food of animal and plant origin [28]. Estimates indicate that about $25 \%$ of the world's food is affected by mycotoxin-producing fungi [25], where the main food contaminants are cereals (corn, rice and wheat) and legumes (beans, peanuts, peas and soybeans), besides rations and processed products [7].

The toxic effects induced by fungal toxins are dependent on the level of intake, duration of exposure, the toxin species, the mechanisms of action and metabolism. When consumed at high levels they trigger acute organic disorders known as mycotoxicoses, many of them can be teratogenic, cancerinogenic, estrogenic, neurotoxic and immunosuppressive [6].

\subsection{Metabolizable and Immunosuppressive Agents}

In the ration when ingested the FUMO have low bioavailability and are rapidly metabolized and excreted. Its mode of action is related to its toxicity in the interference of sphingolipids biosynthesis, which is of great importance for the maintenance of cell 
membrane integrity, regulation of cell surface receptors, ion pumps, regulation of growth factors and other systems vital for the functioning and survival of the cell.

The main mechanism of toxic action of FUMO B1 is related to the inhibition of the biosynthesis of cell membrane sphingolipids, according to Souto et al. [29]. Sphingolipids are present in cell membranes, playing a key role in cell regulation and membrane protein control, mediating cell growth, cell differentiation and death [30].

According to Haschek et al. [31], the FUMO cause immunosuppression and increase the susceptibility of animals to infectious diseases, being immunotoxic generates effects on cellular responses, humoral factors and cytokine mediators of the immune system. The effects on immunity and resistance are often difficult to recognize in the field because the signs of the disease are associated with the infection and not with the toxin [32]. Furthermore, in animal models, the immunosuppressive effects of toxins occur at lower levels of ingestion than the effects of the toxin on othertoxicity parameters, such as feed intake and growth rate.

Pigs are potentially exposed to high FUMO B1 levels in the short-term diet, with swine pulmonary edema (EPS) being the main pathology. FUMO interfere with the metabolism of sphingosine-sphinganine [33], impairing the metabolism of sphingolipids [30].

\subsection{Synergistic Effects of FUMO in Finished Piglets and Pigs}

In the production of animal it was found that the liver and kidney retain most of the absorbed FUMO [34]. Swine is susceptible to poisoning, in which FUMOB contaminated diets cause inappetence and depression, inducing cardiovascular toxicity, pulmonary edema and liver degeneration, and, at high concentrations, can lead to pancreatic, hepatic and renal damage [35]. The heart and the pancreas may also be affected by diets containing FUMOB [32]. Flaccidity and dilation of the cardiac walls were observed in piglets poisoned with FUMO, and liver, lung and kidney involvement may occur [32].

The disease causes pulmonary edema in pigs [36], this edema was first documented in pigs in 1981 in the USA, after exposure to corn contaminated with $F$. verticillioides.

Acute intoxication of pigs by FUMO is clinically easy to detect and is characterized by signs of pulmonary edema. The most characteristic changes in affected animals include anorexia, lethargy, open mouth, increased respiratory rate, jaundice and cyanosis on the skin is more evident in the ears, snout, sclera and mucous membranes. There are also excessive salivation, hepatic encephalopathy syndrome, moist rust on the lungs, and watery diarrhea [37].

The piglets preferentially remained in lateral decubitus position and presented reduced water and feed consumption [32].

In this way, they can be easily confused with malnutrition, genetic deficiency and inadequate management. The lot usually presents significant developmental unevenness of the animals with decreased food intake and weight gain with significant worsening of feed conversion. They have bristles with less brightness, bristles and animals circulate more frequently in the bay without feeding [37].

In male pigs, contamination with 1-10 ppm per FUMO B1 resulted in increased blood cholesterol in the animals, as well as changes in the weight of the pancreas and adrenal glands [38]. The main FUMO B1 lesions in pigs are associated with pulmonary edema, hydrothorax, hepatic nodular degeneration, hyperplasia and esophageal lesions, mainly occurring in chronic intoxications [32].

Haschek et al. [31] describe that FUMO toxins in finished pigs are characterized by lung, liver, cardiovascular and immune system injury and effects on growth rate and carcass composition. The pigs 
develop edema within 4-7 d when fed FUMO B1, containing food or culture material at concentrations of $16 \mathrm{mg} / \mathrm{kg}$. Likewise, pulmonary edema can be fatal within $7 \mathrm{~d}$.

In weaned piglets, cases of pulmonary edema with concentrations of 10-40 ppm with periods of ingestion of four weeks have been detected [31].

In 3-week-old hybrid male piglets consuming FUMO B1 doses of $0.5 \mathrm{mg}$ per kilogram per live weight for day equivalent to 7 ppm of FUMO B1 for 6 d, there was a significant increase in oral Escherichia coli spread, however, there were no deaths, only variation in weight gain [39].

\subsection{Control and Methods of Decontamination by FUMO}

As a precautionary measure to avoid the effects of FUMO in animal husbandry, the United States and the European Union recommend the tolerance limits of $20.0 \mathrm{mg} / \mathrm{kg}$ (millet for pigs) and $5.0 \mathrm{mg} / \mathrm{kg}$ (pork rations), according to Souto et al. [29]. However, there are no tolerance limits for FUMO in animal feed ingredients or in Brazil [29].

The physical decontamination method involves the use of such as activated charcoal, cholestyramine [17], hydrated sodium and calcium aluminosilicate and Egyptian montmorillonite [40] demonstrated effectively that decontaminations methods binds mycotoxins in the gastrointestinal tract of animals, reducing the bioavailability of the toxin in the diet.

Chemical treatment with ammonium hydroxide can reduce FUMO B1 levels in contaminated maize by $79 \%$, since the treatment of maize with $\mathrm{Ca}(\mathrm{OH})_{2}$ can reduce the concentration of FUMO by about $50 \%$ [17].

One way to biologically control $F$. verticillioides is to use an endophyte bacterium, Bacillus subtilis, which reduces the accumulation of FUMO B1 during the life cycle phase of the fungus in which no infection is observed, although this is present [41]. In addition, the fungus competes with the fungus for the same ecological niche in the plant [41].

The use of yeast Exophiala spinifera is able to promote the hydrolysis of FUMO B1 in aminopentol and tricarballylic acid, as well as the decontamination of aminopentol with the release of $\mathrm{CO}_{2}$ [17].

Among field strategies there is the management of insect infestation and previous crop residues, crop rotation, harvest time management and ideal grain storage conditions, soil fertilization, use of biocontrol, application of fungicides, among others [42].

\section{Considerations}

The observation of the synergistic effects in vivo together with the control of FUMO in pig feed is useful epidemiological investigation and public health monitoring of the population. The great demand of food for the breeding of pigs and other animals, increases the difficulty in controlling the contamination by FUMO that can happen during the time of harvest and processing of the animal feed. However, the discovery of the FUMO concentration limits allowed in laboratory analyses for each animal species generates possibilities for better controls of the raw materials supplied in the diets. The following goals are to identify those nations that would have a greater impact of contamination, establish stricter global legislation, assess health benefits as well as economic losses.

\section{References}

[1] Feddern, V. C. G., Tavernari, F. C., Mazzuco, H., Cunha, A., Krabbe, E. L., and Scheuermann, G. N. 2013. "Aflatoxins Importance on Animal Nutrition." In Aflatoxins-Recent Advances and Future Prospects, 1st ed., edited by Razzaghi-Abyaneh, M. Intech Open the Shard, London, 171-95. Accessed November 25, 2018. https://www.intechopen.com/books/aflatoxins-recent-adv ances-and-future-prospects/aflatoxins-importance-on-ani mal-nutrition.

[2] Krska, R., and Molinelli, A. 2007. "Mycotoxin Analysis: State-of-the-Art and Future Trends." Analytical Bioanaytical Chemistry 387: 145-8.

[3] Hussein, S. H., and Brasel, M. J. 2001. "Toxicity, Metabolism, and Impact of Mycotoxins on Humans and 
Animals." Science 167: 101-34. Accessed April 8, 2019. https://www.sciencedirect.com/science/article/pii/S03004 83X01004711.

[4] Placinta, C. M., D’Mello, J. P. F., and Macdonald, A. M. C. 1999. "A Review of Cereal Grains and Animal Feed with Fusarium Mycotoxins." Animal Feed Science and Technology 78: 21-37.

[5] Jurgenson, J. E., Zeller, K. A., and Leslie, J. F. 2002. "Expanded Genetic Map of Gibberella moniliformis (Fusarium verticillioides)." Applied Environmental Microbiology 68 (4): 1972-9.

[6] Köppen, R., Koch, M., Siegel, D., and Merkel, S. 2010. "Determination of Mycotoxins in Foods: Current State of Analytical Methods and Limitations." Applied Microbiological Biotechnological 86: 1595-612. Accessed November 24, 2018. https://link.springer.com/article/10.1007/s00253-010-253 $5-1$.

[7] Iamanaka, B. T., Oliveira, I. S., and Taniwaki, M. H. 2010. "Mycotoxins in Food." Anais da Academia Pernambucana de Ciência Agronômica, Recife 7: 138-61. (in Portuguese)

[8] Wu, F. 2004. "Mycotoxin Risk Assessment for the Purpose of Setting International Regulatory Standards." Environmental Science Technology 38 (15): 4049-55.

[9] Speijers, G. J. A., and Speijeirs, M. H. M. 2004. "Combined Toxic Effects of Mycotoxins." Toxicology Letters 153: 91-8.

[10] Kubena, L. F., Harvey, R. B., and Buckley, C. A. 1997. "Individual and Combined Effects of Moniliformin Present in Fusarium fujikuroi Culture Material and Aflatoxin in Broiler Chicks." Poultry Science 76: 265-70.

[11] Creppy, E. E., Chiarappa, P., Baudrimont, I., Borracci, P., Moukha, S., and Carratú, M. R. 2004. "Synergistic Effects of Fumonisin B1 and Ochratoxin A: Are in Vitro Cytotoxicity Data Predictive of in Vivo Acute Toxicity?" Toxicology 201 (3): 115-23.

[12] Seo, J. A., and Lee, Y. W. 2004. "Natural Occurrence of the C Series of Fumonisins in Moldy Corn." Applied Environmental Microbiology 65 (3): 1331-4.

[13] Labuda, R., Tancinova, D., and Hudec, K. 2003. "Identification and Enumeration of Fusarium Species in Poultry Feed Mixtures from Slovakia." Animal Agriculture Environmental Medicinal 10: 61-6.

[14] Niderkorn, V., Morgavi, D. P., and Aboab, B. 2009. "Cell Wall Component and Mycotoxin Moieties Involved in Binding of Fumonisin B1 and B2 by Lactic Acid Bacteria." Journal of Applied Microbiology 106 (3): 977-85.

[15] Grenier, B., Bracarense, A. P., and Schwarts, H. E. 2012. "The Low Intestinal and Hepatic Toxicity of Hydrolyzed Fumonisin B1 Correlates with Its Inability to Alter the
Metabolism of Sphingolipids." Biochemical Pharmacology 83 (10): 1465-73.

[16] Dilkin, P., Mallmann, C. A., and Almeida, C. A. A. 2002. "Fumonisin Production by Fusarium moniliform Strains according to Temperature, Humidity and Culture Time." Brazilian Journal Microbiology 33 (2): 111-8. Accessed November 25, 2018. http://dx.doi.org/10.1590/S1517-83822002000200003. (in Portuguese)

[17] Soriano, J. M., and Dragacci, S. 2004. "Intake, Decontamination and Legislation of Fumonisins in Foods." Food Research International 37 (4): 367-74.

[18] Seefelder, W., Knecht, A., and Humpt, H. U. 2003. "Bound Fumonisin B1: Analysis of Fumonisin-B1 Glyco and Amino Acid Conjugates by Liquid Chromatography-Electrospray Ionization-Tandem Mass Spectrometry.” Journal Agriculture Food Chemistry 151: 5567-73.

[19] Fandohan, P. 2003. "Infection of Maize by Fusarium Species and Contamination with Fumonisin in Africa." African Journal of Biotechnology 2: 570-9. Accessed November $\quad 10, \quad 2018$. https://www.researchgate.net/publication/27797061_Infe ction_of_maize_by_Fusarium_species_contamination_wi th_fumonisin_in_Africa.

[20] Marín, S., Magan, N., and Serra, J. 1999. "Fumonisin B1 Production and Growth of Fusarium monilifomre and Fusarium proliferatum on Maize, Wheat and Barley Grain.” Food Microbiology and Safety 64 (5): 921-4.

[21] Paterson, N. R. R., and Lima, N. 2010. "How Will Climate Change Affect Mycotoxins in Food?" Food Research International 43: 1902-14.

[22] Ono, S. Y. E., Yoshitsugu, S., and Homechin, M. 1999. "Effect of Climatic Conditions on Natural Mycoflora and Fumonisins in Freshly Harvested Corn of the State of Parana, Brazil." Mycopathologia 147: 139-48.

[23] Kawashima, M. L., and Soares, V. M. L. 2006. "Incidence of Fumonisin B1, Aflatoxins B1 and B2, G1 and G2, Ochratoxins A and Zearalenone in Maize Products." Ciências Tecnológicas Alimentares 26 (3): 516-21. (in Portuguese)

[24] Mallmann, C. A., and Dilkin, P. 2007. Mycotoxins and Mycotoxicoses in Swine. 1st ed., Brasil: Sociedade Vicente Pallotti, 105-27. (in Portuguese)

[25] Bryden, W. L. 2007. "Mycotoxins in the Food Chain: Human Health Implications." Asia Pacific Journal of Clinical Nutrition 16 (Suppl. 1): 95-101.

[26] Shephard, G. S., Thiel, P. G., Stockenström, S., and Sydenham, E. W. 1996. "Worldwide Survey of Fumonisin Contamination of Corn and Corn-Based Products.” Journal AOAC Internal 79 (3): 671-86.

[27] Bernd, P. L. 2010. "Fusarium verticillioides and 
Fumonisin in Maize Production Chain: Mathematical Modeling and Control Strategy." M.Sc. thesis, Ciência e Tecnologia de Alimentos, Londrina. http://www.dominiopublico.gov.br/pesquisa/DetalheObra Form.do?select_action=\&co_obra=194874.

(in Portuguese)

[28] Amelin, V. G., Karaseva, N. M., and Tret'yakov, A. V. 2013. "Chromatographic Methods for the Determination of Mycotoxins in Food Products." Journal of Analytical Chemistry 68 (3): 195-205.

[29] Souto, C. M. C. P., Ramalho, L. N., and Gregorio, M. C. 2015. "Weight Gain, Feed Intake and Organ Histology of Piglets Fed Diets Containing Low Levels of Fumonisin B1.” Brazilian Veterinary Research 35 (5): 451-5. (in Portuguese)

[30] Turner, P. C., Nikiema, P., and Wild, C. P. 1999. "Fumonisin Contamination of Food: Progress in Development of Biomarkers to Better Assess Human Health Risks." Mutat Res. 443 (1-2): 81-93. Accessed November 25, 2018. https://www.sciencedirect.com/science/article/pii/S13835 74299000125.

[31] Haschek, W. M., Gumprecht, L. A., Smith, G., Tumbleson, M. E., and Constable, P. D. 2001. "Fumonisin Toxicosis in Swine: An Overview of Porcine Pulmonary Edema and Current Perspectives." Environmental Health Perspective 109: 251-7. Accessed November 29, 2018. https://www.jstor.org/stable/3435016?seq=1\#page_scan_t ab_contents.

[32] Dilkin, P., Direito, G., Simas, M. M., Mallmann, C. A., and Correa, B. 2010. "Toxicokinetics and Toxicological Effects of Single Oral Dose of Fumonisin B1 Containing Fusarium verticillioides Culture Material in Weaned Piglets." Science 185: 157-62. Accessed January 23, 2019. https://www.researchgate.net/publication/42588282_Toxi cokinetics_and_toxicological_effects_of_single_oral_dos e_of_fumonisin_B1_containing_Fusarium_verticillioides _culture_material_in_weaned_piglets.

[33] Cirillo, T., Ritieni, A., Galvano, F., and Cocchieri, R. A. 2003. "Natural Co-occurrence of Deoxynivalenol and Fumonisins B1 and B2 in Italian Marketed Foodstuffs." Food Additives \& Contaminants 20 (6): 566-71.

[34] Williams, L. D., Bacon, C. W., Meredith, F. I., and Franzluebbers, A. J. 2003. "Leaching and Biding of Fumonisins in Soil Microcosms.” Journal Agriculture,
Food. Chemistry 51: 685-90.

[35] Lovatto, P. A., Lehnen, C. R., and Bertolin, N. C. K. 2007. "Relationship between Fumonisins in the Nursey Piglet Diet and Occurrence Sucking Addiction, Performance and Characteristics of Some Organs." Ciência Rural 37 (4): 1091-6.

[36] Haschek, M. W., Motelin, G., Ness, D. K., Harlin, K. S., Hall, W. F., Vesonder, R. F., Peterson, R. E., and Beasley, R. 1992. "Characterization of Fumonisin Toxicity in Orally and Intravenously Dosed Swine." Mycopathology 117: 83-96.

[37] Sobestiansky, J., and Barcellos, D. 2007. "Mycotoxins and Interactions in Swine Farming." In Pig Diseases, edited by Mallmann, A. C., and Dilkin, P., Goiânia: Cânone Editorial, 581-610. (in Portuguese)

[38] Rotter, B. A., Thompson, B. K., Prelusky, D. B., Trenholm, H. L., Stewart, B., Miller, J. D., and Savard, M. E. 1996. "Response of Growing Swine to Dietary Exposure to Pure Fumonisin B1 during an Eight-Week Period: Growth and Clinical Parameters." Natural Toxins 4: 42-50.

[39] Oswald, I. P., Desautels, C., Laffitte, J., Fournout, S., Peres, S. Y., Odin, M., Le Bars, P., Le Bars, J., and Fairbrother, J. M. 2003. "Mycotoxin Fumonisin B1 Increases Intestinal Colonization by Pathogenic Escherichia coli in Pigs." Applied and Environmental Microbiology 69: 5870-4.

[40] Aly, S. E., Abdel-Galil. M. E., and Abdel-Wahhab, M. A. 2004. "Application of Adsorbent Agents Technology in the Removal of Aflatoxin B1 and Fumonisin B1 from Malt Extract." Food Chem Toxicology 42: 1825-31. Accessed October 29, 2018. https://www.researchgate.net/publication/8362505_Appli cation_of_adsorbent_agents_technology_in_the_removal _of_aflatoxin_B1_and_fumonisin_B1_from_malt_extract.

[41] Bacon, C. W., Yates, I. E., and Meredith, F. 2001. "Biological Control of Fusarium moniliforme in Maize." Environmental Health Perspectives 109: 325-32. Accessed April 20, 2019. https://www.jstor.org/stable/3435026?seq=1\#page_scan_t ab_contents.

[42] Munkvold, G. P. 2003. "Epidemiology of Fusarium Disease and Their Mycotoxins in Maize Ears." European Pathology 109: 705-13. Accessed November 20, 2018. https://link.springer.com/article/10.1023/A:10260783242 68. 